\title{
THE EFFECT OF WATCHING ENGLISH MOVIES WITH SUBTITLES ON ESP STUDENTS' CONTENT AND VOCABULARY COMPREHENSION A STUDY CONDUCTED AT AN INDONESIA POLYTECHNIC ENGINEERING
}

\author{
Eny Kusumawati \\ eny-k@pens.ac.id \\ Departemen Teknik Mekanika dan Energi, Program Studi Teknik Mekatronika \\ Politeknik Elektronika Negeri Surabaya
}

\begin{abstract}
This research is focusing on the impact of English movies with subtitles on content comprehension of English movies and vocabulary comprehension. With fifty-six (56) students of Politeknik Elektronika Negeri Surabaya was selected randomly of English subject. Activate the quasi-experimental study, a movie with tittle Transcendence was selected based on the ESP content and language level difficulty. With two intact groups, they were group A and group B. They watched the same movie, class A watched it with English subtitles and class B without subtitles. After watching the movie, the participants answered the relevant multiple-choice vocabulary, content comprehension questions, and questioners. The data gathered were subjected to the statistical procedure of paired sample t-test. The results showed that subtitles have a positive impact on content comprehension of English movies. It can be concluded that the participants comprehend the subtitled movie better than the one without it. Moreover, in this statistical study, it is found that the subtitles did not have an effect on participants' vocabulary comprehension. The pedagogy of this study is to allow the lecturer use some film to enrich the teaching materials for reading class in ESP.
\end{abstract}

Keywords: ESP, English movies, subtitles, content comprehension, vocabulary comprehension.

\section{BACKGROUND}

Teaching English in the field of ESP has become more challenging, in this study, the Engineering field is the point of view. To help the learners' mastery their English skills, the English teachers should provide the quality teaching materials to develop themselves. The appropriate strategy to teach, and good quality of teaching materials will engage them, to update simultaneously as the bridge that will ensure the students to learn.

The characteristics of ESP as Dudley Evans and St.John (1998) mentioned that (1) ESP is defined to meet specific needs of the learners, (2) ESP makes use of underlying methodology and activities of discipline it serves, (3) ESP is centered on the language appropriate to these activities in terms of grammar, lexis, register, study skill, discourse and genre. At the conceptual level, Hutchinson \& Waters (1987: 16) noted that ESP is divided into two main types and differentiated according to whether the learner requires English for 
Academic Study (EAP: English for academic purposes) or for work (EOP/EVP/ VES: English for Occupational Purposes/ Vocational English as a Second Language).

To fulfill the lack of ESP condition in this study, movie is being the choice to present as the English material. The appropriate movie genre is the best choice way to avoid the boredom situation. Wilkin (1972) emphasizes the importance of word knowledge by saying "you can communicate in a language without grammar, but you cannot communicate without a word knowledge". Relate to this, using films to teach a foreign language can help motivate students and remove some of the anxiety of not knowing the language. Movie not only allow the teacher to introduce variety and reality into the classroom, but discussions based on movie content allow students to bring their own background knowledge and experiences into the discussion.

Moreover, almost everyone has the same opinion that study language with watching a movie is pleasurable. Thammineni (2016) in his study said that watching movies in English classroom helps in many ways, especially for L2. In his studies, he said that (1) Listening Skills: The learners English being used in a very natural way. Some parts may be speaking too fast for the learners to understand but it will be a perfect way for the learner to get used to hearing native speakers talk to each other. We will also hear informal English and slang words and phrases that we often do not find in books or dictionaries. (2) Speaking Skills: Hearing natives speak will also help learners speaking skills, especially fluency. We hear how to link words together and where to put information on certain words and sentences. Watching films with peer group and speak about them afterward or the learners could even find movie scripts online and act out scenes with their friends in language classroom shall yield good results in giving the opportunity to develop speaking skills. (3) Pronunciation: We all know that English pronunciation is extremely difficult and when we read words it is hard to know how they should be said. Hearing native English speakers' talk to each other will help to hear how words are pronounced. If we are using English subtitles, we will also be able to see how the words are written. (4) Vocabulary: By watching English movies, we hear many new words and phrases, especially idioms and colloquial expressions. Writing down any new words or phrases those are heard while watching a movie or remembering them for ready use of them in our conversations is a worthy experience. If we don't understand a few new words, it also gives us an opportunity to refer to the dictionary for the meaning of them (5) Put Knowledge into Practice: In English classes, we learn a lot of vocabulary and grammar but the learners may not know how to use it in real life. Watching English films will help them understand how to use all the learned knowledge in everyday situations.

Based to some theorists, in this study, the use of subtitle in teaching English for L2, especially in the field of ESP can be further improved by using the right way and selection of teaching materials. Caption and subtitles as a form of scaffolding for audiovisual materials have gained much attention in second or foreign language (L2) learning in recent years and various studies report their positive effects on learners' listening comprehension (Hosogoshi: 2016). This medium provides not only rich aural input, but this is also the use of subtitle can expose learners to visual input as well. Subtitles in any language are the best way to 
understand about the movie from other cultures, language, and country. And for learners, subtitles might offer a new path to language learning and comprehension. The use of subtitled movie is more effective at improving overall comprehension than non-subtitled movies. Students who watch subtitled movies to learn a foreign language have shown improvement in reading and listening comprehension, word comprehension, decoding skills, motivation and vocabulary acquisition.

Subtitles allow an accented language become intelligible to any viewer. To understand the content of a movie, subtitle plays the important role to bridge the audience need, such as deliver the word according to the audience native and culture. Because, if the audience does not understand the meaning of the utterance, automatically the audience would read and process the subtitles in their native. But, when the subtitles are in the language of the film, the audience is able to hear the new accent while reading the text. Simultaneously hearing and reading foreign words help incorporate what the audience hears through their phonetic understanding of the language, then it can understand the future words as they come up and familiarize themselves with the sounds of their new language. Grignon, Lavaur \& Blanc (2005) compared three versions of a film sequence (that is, dubbed, subtitled, and original versions) and they found that the dubbed and subtitled versions lead to better performance than the original version.

Even, audiovisual media are closer to real life because visual clues and context make it exactly to see and view the message as much as listening (Baltova, 1994: 508). Some researcher has shown, listening comprehension is an "active, cognitive process" involving "speculating and predicting" rather than individual sound deciphering because incomplete acoustic input often necessitates filling in missing information (Noblitt, 1995). Comprehension is also influenced by visual information and cultural knowledge (for example interpreting facial expressions), as lip-reading research has demonstrated (Baltova: 1994).

Then, related to comprehension, some still argue that the improved listening comprehension resulting from the specific context of a captioned audiovisual program does not necessarily prove student's ability to better understanding or comprehending the scene without captions. The caption is the aids with phonological visualization of aural cues in the minds of listeners, who become more certain of ambiguous input, can more accurately form a memory trace of the words, and can later more easily identify same sounds without textual support (Bird \& William; 2002. Michael: 2009). Moreover, most all of studies about subtitles proved that subtitles could improve language learning, vocabulary acquisition, and comprehension (Hayati \& Mohmedi: 2009, Ebrahimi, \& Bazaee: 2016. İşcan: 2017).

Some research and studies have more specifically focused on the effect of subtitles on vocabulary learning. Bird and Williams (2002) conducted two studies examining the effect of single modality (sound or text) and bimodal (sound and text) presentation on word learning, and both experiments led to the conclusion

Some experts have revealed that movies used in EFL classroom become an essential part of a tool to gain the student's ability to develop their English mastery. This is based on 
the fact that movies provide exposures to the reality of language, used in authentic settings and in the cultural context which the foreign language is spoken. They also have found that movies catch the learners' interest and it can positively affect their motivation to learn (Kusumarasdyanti, 2004; Luo, 2004).

Find the appropriate tool's film in the field of ESP is quite challenging, especially in the field of Engineering. Teachers should find the appropriate film, which can attract the students' attention and curiosity about their field, such as Hollywood film with the famous and popular actors. The box office film is the best choice to deliver this aim. Using English language movies to develop their vocabulary comprehension in the main goal of the study as English language movies possess the benefit of authentic input. Motivating students and more opportunities to develop their vocabulary and their comprehension.

\section{Objectives and significance of the study}

In light of the background study, the research questions are formulated as follows:

1. Is there any influence using subtitles and without subtitle on the students' ESP reading comprehension?

2. Is there any influence on the group treated with movie subtitle and the group treatment without movie subtitle on their comprehension of the movie?

3. Is there any influence on the group treated with movie subtitle and the group treatment without any subtitle on their vocabulary enhancement?

\section{METHODOLOGY}

\section{Participants}

The participants in this study were the students of Politeknik Elektronika Negeri Surabaya, in the 5th semesters of Mechatronics department. The total participants were 56 students. Their level of proficiency is intermediate. The study took place for a semester (3 months with eight meetings). The study was conducted on a sample of two groups: an experimental group exposed to a video which accompanied the reading section activity and another group taught conventionally. The discussions of the findings were presented according to the research questions of the study

\section{Methods}

This study was quasi-experimental with pretest and posttest design. To support this study, explicit instructions and natural translation methods were used in both classes. The subjects were the fifth semesters of Mechatronics Department and Industrial electronics 
department of Politeknik Elektronika Negeri Surabaya. They chose because they had the same characteristics and level of English.

In order to determine which group belong to the A group which use subtitles and the B group which belongs to the class without subtitles, the coin lottery was employed.

Prior the experiment, both classes were ensured to be equal in all aspects by observing both classrooms, interviewing the English teacher taught in both classes and using school documents' English scores in the previous semester. Those were carried out as the efforts to reduce the threat towards internal validity, in this case, is a selection (Ary, Jacobs \& Sorensen. 2006: 298). The data of students of the two classes are shown in table 1.

Table 1 The Qualitative Features between two classes.

\begin{tabular}{cllc}
\hline No & Features & $\begin{array}{l}\text { With } \\
\text { Subtitle } \\
\text { Group } \\
\text { (Group A) }\end{array}$ & $\begin{array}{l}\text { Without } \\
\text { subtitle } \\
\text { Group } \\
\text { (Group B) }\end{array}$ \\
\hline 1 & $\begin{array}{l}\text { Number of } \\
\text { students } \\
\text { Mean scores for } \\
\text { English Subject } \\
\text { The schedule of } \\
\text { English subject }\end{array}$ & Monday 3-4 & 27 \\
\hline
\end{tabular}

Taking the qualitative features in those two classes, it can be concluded that they were not significant regarding students' number in the portion of mean scores for English subject. It can assume that both classes were homogenous which play an essential role before the experimental research. It should ensure that the subjects of the study in both groups were equal to avoiding bias result.

Then, the students' English scores of both classes will be compared to determine the effect of the treatment on both groups according to their proficiency.

Before the treatments, the researcher and the English teacher collected the students' English data from their previous semester. The data was conducted on both experimental classes to get the condition of the classroom and to ensure that both classes were equal in term of language achievement.

Next was the experimentation; both two classes had explicit instruction given in the class. Both classes had reading classes with audio-visual aid to support the students comprehend of the topic discussed. After four meetings have given, the posttest was conducted. Due to the posttest, the teacher and the writer prepared the movie to present to 
the class. After watching the movie, the students would get the reading test in the objective. After finishing the test, the instruments must be collected. Then the next instrument was, the questionnaires shared to the students. It used to get the students opinion and motivation about the using of the movie as a part of the instrument in English class.

In the process of teaching and learning, a teaching schedule alternation between the teacher and the researcher was applied in order that to minimize the possible threats, particularly in this case is that the teacher plays a role on the students' motivation. By alternating the schedule of teaching between the teacher and the researcher, the teaching and learning atmosphere was conditioned like the usual classes so that the students would not be suspicious that they were under the research. The discussion on the detailed lesson plan, including teacher strategy, media/ materials, and assessment was carried out to the process of experiments. So that to ensure that the teacher could apply the lesson plan with the explicit instruction given. The details explanations on the lesson plan were given to the teacher before the starting class. The detailed teaching schedule alternation between the researcher and the English teacher are shown in table 2.

Table 2. Teaching Schedules

\begin{tabular}{cll}
\hline Meeting & $\mathbf{1}^{\text {st }}$ Experimental Group & \multicolumn{1}{c}{ 2 Experimental Group } \\
\hline 1 & The English teacher & The researcher \\
2 & The researcher & The English teacher \\
3 & The English teacher & The researcher \\
4 & The researcher & The English teacher \\
5 & The English teacher & The researcher \\
6 & The researcher & The English teacher \\
\hline
\end{tabular}

This swap was based on the consideration that every change is happening in the posttest for experimental groups did not have any relationship with the teacher in the group.

Before the treatment applies, the English teacher and the researcher discussed all the planning, the threats, the solutions and also some of another solution when another plan should apply as the problem solver. All the lesson plans for six meetings for both classes had been set by the researcher. She set some of short movie or clips with and without subtitles to apply in the classes, to familiarize the students with the movie in the class. The revised lesson plans then were communicated in detail to the English teacher, so there was no misunderstanding between the researcher and the teacher regarding the implementation of the activities for the two groups. Based on the discussion, some revisions were made. Some materials and movies were prepared.

After all the lesson plans and media had been ready for the experimentation process, the English teacher and the researcher set the schedule for the experimentation for the groups. Then the researcher took the students' data from the previous semester to take it as the pretest 
data. It conducted from both experimental classes to draw the condition of the classroom and to ensure that both classes were equal in term of language learning achievement.

The final stage of the data collection was administering the post-test. After administering the post-test, the scoring test was carried out. The form of the scoring was that each correct item was counted as one point meanwhile the wrong one was counted as zero points. Then, the number of correct items was divided by a total number of the items and multiplied by 100 as the maximum score. The score of each student, then, was tabulated in the computer for further analysis.

Two types of data collection were used:

1. The quiz is given at the end of the posttest session.

2. Questionnaires.

To develop the study, another data conducted:

1. Data are collected through students' and teachers' questionnaire which investigates their attitudes towards movie-based teaching and learning. The questionnaires designed in the form of a 5 point Likert scale ranging from 'Strongly Disagree' to Strongly Agree”. The questionnaires were distributed to the English teacher to 56 students.

2. The quiz was given to both controlled and experimental group at the end of the reading section

\section{PROCEDURES}

\section{Data collection}

For the purpose of this study, the same film was chosen, and used in class reading for both groups (controlled and experimental). However, classroom procedures and teaching methods were different for each group. This movie was chosen because it is required on the syllabus, one of the syllabi discuss Artificial Intelligent and Nano Satellite for future technology.

The A group, the movie trailer introduced the core theme, students were also given true/False questions as a brainstorming activity. All through movie class, students viewed segments video material.

The B group used the usual procedure and activities for the in-class reading. In this class and case, at the beginning of the class, students were given a short list of vocabulary words phrases used in the book in order to prepare them for better understanding the story. 
After watching the movie, both groups receiving questionnaires whose aims to elicit students' feedback regarding using the movie in the classroom and to investigate the relationship between movie viewing and student's performance.

After movie viewing, students of both groups were given quiz with vocabulary and reading activities. The vocabulary and reading consisted of comprehension questions in objective test, true/false questions.

\section{a. Pretest}

To investigate the effects of subtitled clips on new vocabulary development, SPSS 19 was run. The result obtained from the pretest of all the groups are presented that the mean score of group A is 50.0741, and the mean score of group B is 50.5517 .

The result showed that all groups are almost the same in terms of their vocabulary knowledge, and there is no significant difference between them. To analyzed this result, SPSS 19 was used.

\section{b. Post Test.}

After analyzing the pretest result, at the end of the treatment, the result obtained from the posttest were analyzed. The descriptive statistics of the participants' performance in different groups are shown that the mean score of group A is 51.4815, and the mean score of group B is 38.4828 .

The mean score of each group and comparison with the mean obtained from pretest reveal that all groups have performed better on posttest and the mean of all groups significantly increased. As shown on group A with mean score 51.4815, the group with subtitle significantly outperformed the other groups and had the highest mean score. The experimental without subtitle group is lower the group with subtitle.

\section{DISCUSSION}

\section{Is there any influence on the movie using subtitles and the movie without subtitle on the students' ESP reading comprehension?}

After the process of treatment, the posttest was given to group A, the movie with subtitle, which lasted for 100 minutes for the movie and questioners.

Then the T-test with independent sample testing is used to find out the answer to the research problem whether any difference or no difference between the two groups. Based on the result of the posttest in a group of the movie with subtitles and the group of movies without subtitle, it was shown that the mean score of the groups were 51.4815 and 38.4828 respective. 
Roughly, it can be concluded that the main score of the A group, the group with movie subtitle was higher than the group B, the group without movie subtitle.

\section{The difference in comprehension between the group which occupied with subtitle and the group $B$ which occupied without subtitle}

Based on the result of posttest of the group of students with subtitle movie and the group without subtitle movie on their comprehension, which is used T-test with independent sample testing to find out the answer of the research problem, the mean scores of the group with subtitle movie is 46.6667 and the group without subtitle movie is 34.0690 respectively. It can be concluded that the main score of the group with subtitle movie was significantly higher than the group without subtitle.

\section{The difference in vocabulary achievement between the group which is occupied with subtitles and the group which is occupied without subtitle.}

Based on the posttest analysis of the group with subtitle movie and the group without subtitle movie, which is used T-test with independent sample testing to find out the answer of the research problem, it was revealed that the mean score for the group with subtitle is 5.0370 and the group without subtitle is 4.3448 . It is revealed that there is no significantly different. They do not have any difference. It means that the test results from both groups showed no increase in vocabulary.

\section{CONCLUSION}

Based on the statistics data, there were set 2 groups of students, a group of students with movie subtitle and the group of students without movie subtitle. They were under the same treatment with two different media of ESP vocabulary and comprehension (with and without subtitles movie).

Overall, in this research study, both groups showed enthusiastic about the movie as their media for vocabulary comprehension. Both groups have significant development on vocabulary about the movie. However, unfortunately, it did not follow with the comprehension, according to the statistical calculation, it proofed that the students' comprehension did not develop as the other variable. The students' comprehension limited to the film only; they fail to develop themselves to gain and connect to other subject's relatives. This research on watching a movie with subtitle has shown that the movie is not only means of entertain, but they can assist learners to comprehend the language they speak in many ways, also many accents (Ebrahimi, Bazaee; 2016).

However, in this research proofed that subtitle did not affect the students' vocabulary because this movie was presented once only. Perhaps, at present more than once would give more benefit to the L2 to develop their vocabulary better. 
To enrich the pedagogy of ESP, it allows the future researchers to dig this research deeper and further expanding the fields. Some aspects perhaps become the future variables considerations. 


\section{BIBLIOGRAPHY}

Ary, Donald. Jacobs, Lucy Cheser. Razavieh, Asghar. Sorenses, Christine K. 2006. Introduction to research in Education 8th Edition. Belmont, Wardsworth.

Baltova, I. 1994). The impact of video on comprehension skills of core French students. The Canadian Modern Language Review. P. 507 - 532.

Baltova, I. 1999. Multisensory language teaching in multidimensional curriculum: The use of authentic bimodal video in core French. Canadian Modern Language Review. P. 32-48.

Bird, S \& J.N. Williams. 2002. The effect of bimodal input on implicit and explicit memory: An investigation of within-language subtitling. Applied Linguistics. P. 509-533.

Dudley-Evans, Tony. Jo St. John, Maggie. 1998. Development in English for Specific Ourposes. A Multy Disciplinary Approach. Cambridge: CUP. 301 pp. ISBN 0 521 59675-0 (Paperback)/ 0 521 59329-8 (Hardback).

Ebrahimi, Yasser. 2016. The Effect of Watching English Movies with Standard Subtitles on EFL Learners' Content and Vocabulary Comprehension. Journal of Applied Linguistics and Language Research. Vol. 3, Issue 5, 2016. Pp. 284-295. ISSN : $237-760 X$

Grignon, P., J.M. Lavaur \& N. Blanc. 2005. The effects of subtitles on film understanding (online).

Available sites.google.com/site/jeanmarclavaur/grigrolavaurblanc2007.pdf

Hayati, A. and Mohmedi, F. 2011. The effect of films with and without subtitles on listening comprehension of EFL learners. British Journal of Education Technology.

Hinkin, Michael. 2009. Comprehension of multiple channel messages: Are subtitles more beneficial than soundtracks?. Online, available: http://krex.kstate.edu/dspace/bitstream/2097/1679/1/MichaelHinkin2009.pdf.

Hutchinson, Tom. Waters, Alan. 1987. English for Specific Purposes. A Learning Centered Approach. ISBN 978-0-521-31837-2

Hosogoshi, Kyoko. 2016. Effect of Captions and Subtitles on the Listening Process: Insight from EFL Learners' Listening Strategies. The Jalt Call Journal. ISSN 1832-4215. Vol. 12, No. 3 Pages 153-178.

İşcan, Adem. 2017. Using Films in Vocabulary Teaching of Turkish as a Foreign Language. Journal of Education and Training Studies. Vol. 5, No. 6; May 2017. ISSN 2324-805X E- ISSN 2324-8068. Published by Redfame Publishing.

Ismaili, Merita MA. 2013. The effectiveness of Using Movies in the EFL Classroom. A Study Conducted at South East European University. Academic Journal Interdisciplinary Studies. Published by MCSER-CEMAS-Sapienza University of Rome. E-ISSN 2281-4612 ISSN 2281-3993. 
Kusumarasdyati. 2005. Subtitled Movie DVDs in Foreign Language Classes, Monash University. Online. Available: http://www.aare.edu.au/06pap/kus06105.pdf.

Thammineni, Hari Babu. (2016). Movies Supplement English Classroom to be Effective in Improving Students' Listening and Speaking Skills - a Review. International Journal of Studies in English Language and Literature (IJSELL) Vol 4, Issue 6, June 2016, PP 35- 37. ISSN 2347-3126 (print) \& ISSN 2347-3134 (online).

Wilkin, David Arthur. 1972. Linguistics in Language Teaching. ISBN 0726720070 9780726720079. Edward Arnold, Australia. 